This article was downloaded by: [University of North Carolina]

On: 21 February 2013, At: 06:04

Publisher: Routledge

Informa Ltd Registered in England and Wales Registered Number: 1072954 Registered office: Mortimer House, 37-41 Mortimer Street, London W1T 3J H, UK

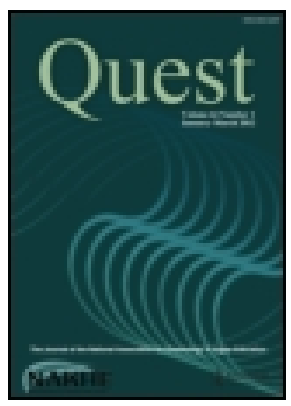

\title{
Quest
}

Publication details, including instructions for authors and subscription information:

http:// www. tandfonline.com/ loi/ uqst20

\section{Integration: The Key to Sustaining Kinesiology in Higher Education}

\author{
Diane L. Gill ${ }^{a}$ \\ ${ }^{a}$ Dept of Exercise and Sport Science, University of North \\ Carolina at Greensboro, Greensboro, NC, 27402 E-mail: \\ Version of record first published: 14 Feb 2012.
}

To cite this article: Diane L. Gill (2007): Integration: The Key to Sustaining Kinesiology in Higher Education, Quest, 59:3, 269-286

To link to this article: http:// dx.doi.org/ 10.1080/00336297.2007.10483552

\section{PLEASE SCROLL DOWN FOR ARTICLE}

Full terms and conditions of use: http://www.tandfonline.com/page/terms-andconditions

This article may be used for research, teaching, and private study purposes. Any substantial or systematic reproduction, redistribution, reselling, loan, sub-licensing, systematic supply, or distribution in any form to anyone is expressly forbidden.

The publisher does not give any warranty express or implied or make any representation that the contents will be complete or accurate or up to date. The accuracy of any instructions, formulae, and drug doses should be independently verified with primary sources. The publisher shall not be liable for any loss, actions, claims, proceedings, demand, or costs or damages whatsoever or howsoever caused arising directly or indirectly in connection with or arising out of the use of this material. 


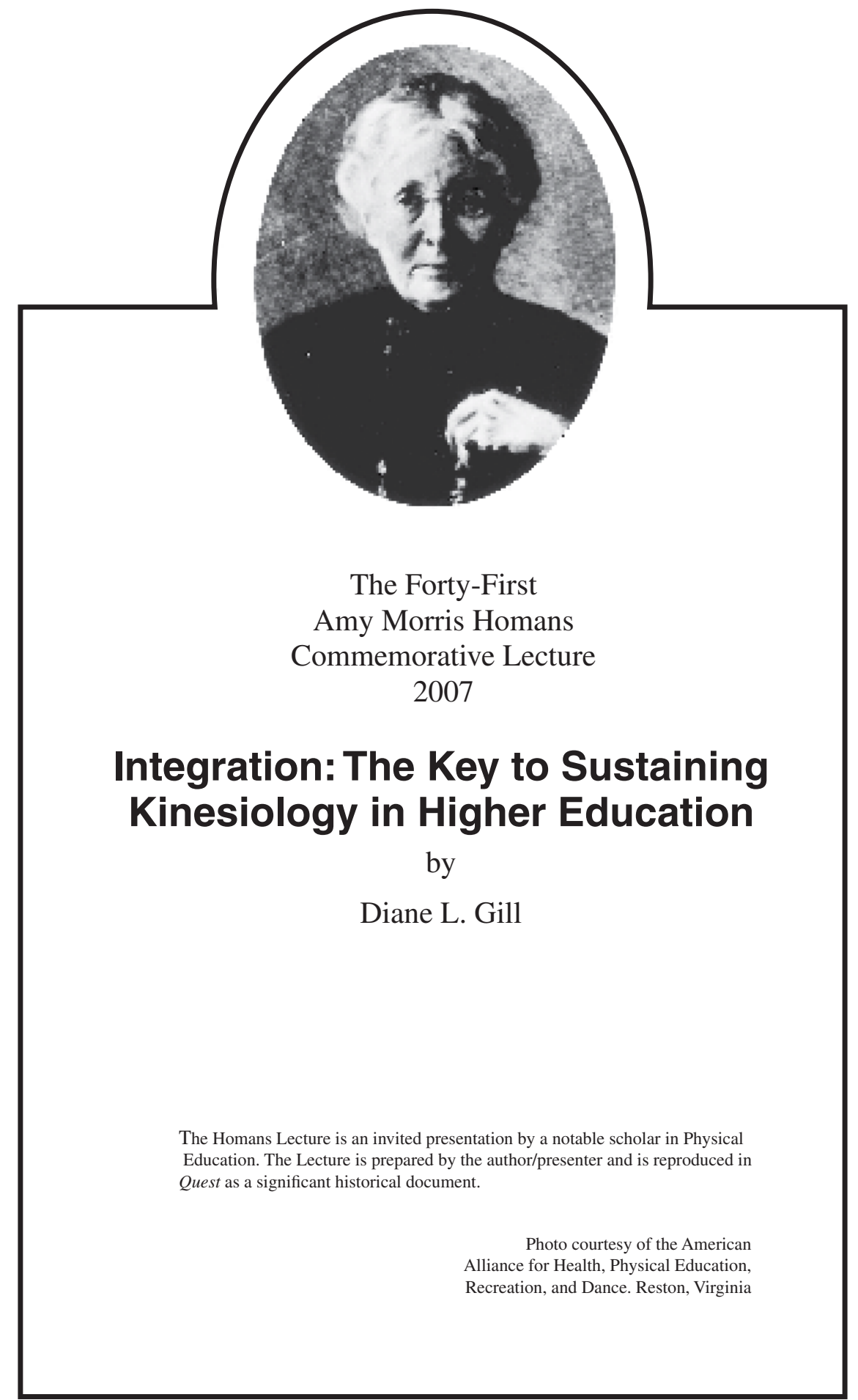




\title{
Integration: The Key to Sustaining Kinesiology in Higher Education
}

\begin{abstract}
Diane L. Gill
Integration is the key to sustaining kinesiology as an academic and professional discipline in higher education. Following the vision of Amy Morris Homans, this paper focuses on integration in three ways. First, integration of our multidisciplinary scholarship, with a clear focus on physical activity, is essential to sustaining kinesiology as a unique scholarly area in higher education. Second, integration of academic scholarship and professional practice is essential to sustaining kinesiology as a scholarly profession. Finally, integration implies an active commitment to inclusion and public service, and that is critical to give meaning and relevance to kinesiology. At its best, kinesiology is an integrative professional discipline that serves the public by promoting health and well-being for all through physical activity. All forms of integration are integral to sustaining kinesiology in higher education.
\end{abstract}

It is an honor to present the Forty-First Amy Morris Homans Lecture. Indeed, Homans' life and work illustrate the underlying theme of this paper-integration is the key to sustaining kinesiology in higher education. Thus, the paper begins with the requisite, but much deserved, tribute to Amy Morris Homans. That tribute sets the stage for the main themes, as Homans clearly established a sustainable professional discipline of kinesiology. Moreover, Homans' vision and actions illustrate the key role of integration in sustaining our professional discipline. After discussing Homans' legacy, I will briefly turn to sustainability and sustaining kinesiology - what that means and how to do it. The main part of the paper then expands on three key points. That is, to sustain kinesiology in the 21 st century, we need:

- Integration as an academic discipline;

- Integration as a professional discipline; and

- Integration as inclusion and social justice.

Obviously these three themes overlap, and indeed, are integrated. Moreover, these points are not totally new. The key message was given by Roberta Rikli (2006) in last year's Homans Lecture, and indeed, many of our visionary leaders have offered similar sage advice. I will repeat and re-emphasize several of those points to remind us to see the vision as we chart our path to sustainability for kinesiology in higher education.

The author is with the Dept of Exercise and Sport Science, University of North Carolina at Greensboro, Greensboro, NC 27402. E-mail: dlgill@uncg.edu 


\section{Amy Morris Homans: The Tribute and Sustaining Vision}

Like previous Homans lecturers, I searched for connections with Amy Morris Homans. Personal connections were quite a stretch, not only because Homans did not leave a biography or personal papers (intentionally), but also because it simply is a stretch. I was born almost exactly 100 years later than Homans, two (small) states over in the Northeast. Like Homans, I'm a Yankee who moved to North Carolina, but unlike Homans, I did not move back for the large part of my professional life. In all sources, Homans is described as always impeccably dressed, and the overstretched personal connections broke on that one.

In turning to Homans' professional values, I find much to connect with. She held high academic standards; her program and students could hold their own in academia as scholars and professionals. She stressed rigor, called on Harvard faculty to teach in her programs, and emphasized what we now call evidence-based practice. Clearly, Amy Morris Homans had a strong commitment to women and social justice, and I'll add more on that later.

\section{Homans' Vision}

Amy Morris Homans started with a vision, and left a legacy-100 years of kinesiology/physical education as a professional discipline. That's sustainability!

Homans' vision (and she clearly had one) was noted in her own statement at a late life tribute:

...we saw the need of something which would lift the life of the masses to a higher level of health and vigor...hygiene and physical education (Homans, 1929; at age 80, quoted in Spears, 1986, p. 143).

In her well-researched examination of Homans' remarkable contributions, historian Betty Spears clearly demonstrated that Homans followed her vision with actions; (Homans) envisioned, pursued, and achieved a profession of physical education for women (Spears, 1986, p. 3). With the sponsorship of Mary Hemenway, the Boston Normal School of Gymnastics (BNSG) was founded in 1889 with Homans as director. As Spears noted,

(Homans) quickly moved...to create a national effort to better women's lives through physical education. She intended to make BNSG the leading school...training generations of teachers who, in turn, would train their students to spread physical education as part of the good life (Spears, 1986, p. 42).

BNSG indeed became a model program for training physical education teachers, in line with her vision. Homans continued to build the professional discipline, and in 1909 BNSG became part of Wellesley with graduate study. By 1936, more than 200 Wellesley graduates held faculty/director positions in the leading physical education programs for women around the country. For example, Mary Channing Coleman, who was my home institution's (UNCG now, Woman's College then) first dean/director, was a Wellesley graduate. By all accounts, Coleman shared 
Homan's vision, including the impeccable dress and professional demeanor as well as rigorous standards.

At both BNSG and Wellesley, Homans demanded a solid, rigorous academic core with high academic and professional standards. The academic programs blended research "experts," liberal arts, and high standards. Moreover, Homans extended her vision and actions to a wider professional field. She did not stay within her own institution, but took the lead in connecting with others and establishing national professional organizations. In 1924 she took the lead in organizing the Association of Directors of Physical Education for Women, forerunner of our current NAKPEHE organization.

\section{Homans' Legacy: Sustained Academic Kinesiology}

Homans' vision was one of a sustainable professional discipline. She clearly focused on the future and recognized the beginnings of her legacy. At age 80, reflecting back, but still looking ahead, she noted...

It is a great satisfaction to see the good work go on in the 3rd and 4th generation of teachers trained by our graduates, and their graduates in turn, an endless chain, and I hope... a constant source of inspiration to generations of teachers yet unborn. (Homans, 1929, quoted in Spears, 1986, p. 143)

How did she do it? The keys to sustainability are in her vision and actions, and Homans' legacy parallels the three-pronged integration theme of this paper. Specifically, Homans' vision and legacy emphasize:

- Academic rigor;

- Professional mission (physical education);

- Commitment to social welfare; and

- Building for the future.

Can we continue to do so well? Can we sustain 100 more years of kinesiology in higher education? In the academy today, 100 days often seems a hope more than a prediction.

\section{Sustainability}

Before focusing on sustaining kinesiology, let's clarify terms. What is sustainability, and what does it mean to sustain kinesiology in higher education? Sustainability is a buzz word in today's academy, as well as in the general public, as illustrated by a recent Chronicle article, titled, "What is a Sustainable University?" (Chronicle, Oct. 20, 2006). According to that article, the answer is: One that promotes the concept of meeting present needs without compromising the ability of future generations to meet their own needs. That definition reflects common understanding, as well as the many definitions and descriptions of sustainability that are accessible through any Internet search. For example, my Google search turned up this sample of several similar sustainability definitions: 
- The ability to provide for the needs of the world's current population without damaging the ability of future generations to provide for themselves. When a process is sustainable, it can be carried out over and over without negative environmental effects or impossibly high costs to anyone involved. (Sustainable table; http://www.sustainabletable.org/intro/dictionary/)

- Meeting the needs of the present without compromising the ability of future generations to meet their own needs. (American Friends Service Committee; http://www.afsc.org/trade-matters/learn-about/glossary.htm)

- The concept of meeting the needs of the present without compromising the ability of future generations to meet their needs. The term was originally applied to natural resource situations in a long term perspective. Today, it applies to many disciplines... Basically, sustainability/sustainable development refers to doing something with the long term in mind. Today's decisions are made with a consideration of sustaining our activities into the long term future. (DANTES is an acronym for Demonstrate and Assess New Tools for Environmental Sustainability). http://www.dantes.info/Projectinformation/ Glossary/Glossary.html

Sustainability has taken hold in higher education, with considerable networking and resource development, illustrated by visiting the website of the Association for the Advancement of Sustainability in Higher Education (AASHE; http://www.aashe. org). As described on the website, AASHE's mission is to promote sustainability in all sectors of higher education-from governance and operations to curriculum and outreach - through education, communication, research, and professional development....AASHE defines sustainability in an inclusive way, encompassing human and ecological health, social justice, secure livelihoods, and a better world for all generations. The vision of AASHE ...is to see higher education take a leadership role in preparing students and employees to achieve a just and sustainable society.... On the model campus all sectors would work collaboratively to advance sustainability, and the content and context of learning would reflect a focus on systemic, interdisciplinary thinking with respect to human health, ethics, future generations, and planetary stewardship (italics added).

As the converging definitions indicate, essentially, sustainability refers to doing something with the long term in mind. Sustainability is inclusive, and can be applied to kinesiology. To achieve sustainability for kinesiology in higher education, we must meet the present needs in society while also building for the future.

\section{Why Sustain Kinesiology?}

Before considering how to sustain kinesiology, we might first ask why we should sustain kinesiology in higher education. Is kinesiology relevant in the world of today and tomorrow? Are kinesiology professionals needed in higher education? The answer is "yes." Kinesiology is relevant in society, and kinesiology is needed in higher education, and that is not just for those of us in NAKPEHE. The professional discipline of kinesiology is relevant today, and perhaps more so, than in Homans' day. Clearly, kinesiology professionals are needed in present and future professional practice. Kinesiology professionals (at all levels) serve the public 
and society. Specifically, we promote physical activity for health and well-being for ALL. Further, all have a right to physical activity as a public health and social justice issue. Ensuring that all members of society can enjoy healthy physical activity is our professional mission in kinesiology at all levels in all settings. Are kinesiology professionals needed in higher education? If not in higher education, where? Yes-if kinesiology professionals are not in higher education, kinesiology professionals will not be anywhere. Kinesiology must be viable in higher education to sustain the profession that is clearly relevant to the larger public.

The larger public recognizes the need for kinesiology professionals as much as, and perhaps more than, those of us in academic kinesiology do. The public recognizes the needs, and population trends and statistics support the view. According to a recent Time article on the future, "Hot jobs, cold jobs," (Time, Oct. 30, 2006) the top five U.S. occupations projected to grow the most by 2014, ranked by the total number of jobs are:

- Postsecondary teachers: 524,000

- Home health aides: 350,000

- Computer-software engineers: 222,000

- Medical assistants: 202,000

- Preschool teachers: 143,000

Postsecondary teacher is clearly the "hot" job, and that implies higher education. Notably it is teachers, not post docs, research professors, or lab directors that will be needed in the future. Higher education is no longer a luxury dominated by the elite, as it often was in Homans' day. Many more postsecondary teachers are needed, and will be needed in the future, to meet the needs of "the masses" seeking higher education. The "hot jobs" list also reflects the growth of allied health professions, which are clearly linked to kinesiology programs and our professional mission in health promotion. Also, the listing of preschool teachers might be noted. Traditionally kinesiology has not emphasized pre-school education, but kinesiology professionals could fill a clear need by promoting and providing healthy physical activity in pre-school education and youth development.

\section{How to Sustain Kinesiology in Higher Education}

Given that kinesiology serves present and future needs, and that higher education is the base for developing and sustaining kinesiology, let's turn more specifically to sustaining kinesiology in higher education. How can we have a sustainable kinesiology that meets the needs of the present with the long term in mind? First, we can revisit the vision and legacy of Amy Morris Homans, and follow these guiding lights: academic excellence, physical activity focus, kinesiology/physical education professional mission, commitment to public welfare and social justice, and finally, intentionally and consciously, build for the future.

Homans' themes are repeated and updated in messages of more current leaders. Gary Krahenbuhl, one of our leading kinesiology scholars, an experienced administrator as university dean and provost, and an astute observer of higher education issues and directions, offered advice in an invited address and Quest 
article (Krahenbuhl, 1998). In discussing the marks of sustainable disciplines, Krahenbuhl cautioned scholars to be vigilant and to:

- Educate current students and the public about the discipline;

- Prepare the next generation of teachers;

- Develop relationships with policymakers, community, government leaders, and decision-makers; and

- Showcase the discipline and its accomplishments.

As Krahenbuhl noted, if a discipline doesn't tell the story, who will? In adding more specific advice for kinesiology and physical education, he advised us to:

- Prepare future faculty with a sense of stewardship for their fields and their institutions. Krahenbuhl advises building for the future and communicating the kinesiology vision to the next generation, and Homans showed us how to do that.

- Build your indispensability to campus, region, and nation. Making our case is increasingly important in today's university; the upper administration, community, and society must see kinesiology as indispensable.

\section{Integration as the Key to Sustaining Kinesiology in Higher Education}

Considering Homans' vision (which is echoed by more current leaders), and Krahenbuhl's insider advice, I return to my three key points: integration, integration, and integration.

\section{Integration as an Academic Discipline}

The first, essential base for sustaining kinesiology in higher education is integration for academic excellence. We must hold to high academic standards and rigor, but that is not enough to make us indispensable. We must be excellent as kinesiology scholars, and that implies an integrative academic focus as a multidisciplinary field. Academic excellence in an identifiable, focused, integrated discipline is essential to sustain any discipline in higher education. Kinesiology clearly is multi-disciplinary, drawing from many (multiple) disciplinary areas (e.g., biology, psychology, sociology), and including multiple subdisciplinary areas (e.g., biomechanics, sport history, exercise physiology). Isolated multiple subdisciplines do not make for an integrated academic area, and a collection of cross-disciplinary areas that simply live together does not constitute an integrated kinesiology discipline. Inter-disciplinary implies actual connections among subareas, and an interdisciplinary kinesiology that integrates subdisciplinary knowledge is essential. As Michelle Magyar (2006) eloquently discussed in her young scholar talk at the 2006 NAKPEHE conference, a transdisciplinary approach goes beyond disciplinary boundaries and challenges the standards and paradigms of knowledge. Magyar further noted that kinesiology can move from an integrative, interdisciplinary base to contribute to transdisciplinary efforts to address such issues as unhealthy lifestyles. Today's universities 
recognize the value of crossing disciplinary boundaries. Kinesiology at its best is an integrative academic discipline; we do this well and can help lead the way in crossing boundaries in higher education.

\section{Integration as a Professional Discipline}

Today, academic excellence is not sufficient for sustainability-we must make a unique contribution; and we do-integration as a professional discipline is kinesiology's unique contribution. That is, we have a professional mission. Like medicine and law, which seem to be able to maintain their professional missions while striving for academic rigor and research excellence, kinesiology must connect (integrate) the academic discipline with professional practice.

\section{Integration as Inclusion and Public Service}

Centrality is a key to indispensability in higher education, and that implies integration to serve the larger central mission. Today's university is concerned about connections with the public-community programs and public service. In kinesiology, we do this well. For example, ongoing community youth development programs, such as those of Don Hellison in Chicago and Tom Martinek at UNCG, are often highlighted by administrators who want to score public relations points with community, legislators, and the larger public (although seldom highlighted at merit time). To effectively serve the larger public mission, kinesiology must be inclusive (in the political, civil rights sense) and must make a commitment to the public good.

\section{Is Kinesiology an Integrative Academic Discipline?}

Kinesiology is described as an integrative academic discipline in public statements such as on the American Academy of Kinesiology and Physical Education (AAKPE) website:

Kinesiology refers to the study of movement. In American higher education, the term is used to describe a multifaceted field of study in which movement or physical activity is the intellectual focus. Physical activity includes exercise for improvement of health and physical fitness, activities of daily living, work, sport, dance, and play, and involves special population groups such as, children and the elderly; persons with disability, injury or disease; and athletes. Kinesiology is a common name for college and university academic departments that include many specialized areas of study in which the causes and consequences of physical activity are examined from different perspectives. The specialized areas of study apply knowledge, methods of inquiry, and principles from traditional areas of study in the arts, humanities and sciences. These areas include exercise and sport biomechanics, history, philosophy, physiology, biochemistry and molecular/cellular physiology, psychology, and sociology; motor behavior; measurement; physical fitness; and sports medicine. An interdisciplinary approach involving several of these areas is often used 
in addressing problems of importance to society. The study of kinesiology can lead to a variety of careers involving teaching, research, coaching and delivery of services related to physical activity and fitness, health promotion, rehabilitation and sports medicine. Positions are found in a variety of settings including schools, colleges and universities, public and private agencies, clinical environments, government, business and the military. (http://www. AAKPE.org; italics added).

Does kinesiology live up to that statement? Does kinesiology include many areas with differing perspectives? Does kinesiology apply knowledge, lead to careers, and address problems of importance to society? The observations and scholarly works from several of our leaders suggest otherwise. Former Homans lecturer Barbara Forker (1986, p. 92) stated “....where are the integrated thinkers...diversification has robbed us of the modern Ms. Homans...we also need leaders who have visions of the larger picture."

Roberta Park (1998), always an astute observer of our historical context and current directions, stated that our field has become a "house divided" and cited three specific issues. First, she cited "Abusing the Academic Discipline Paradigm," referring to the researcher/practitioner split, the subdisciplinary hierarchy with natural science on top, and missing needed psychosocial knowledge, all reflecting failure to maintain the integrative academic discipline. Park also specifically referred to discipline/profession integration in reminding us that "...the notion of a discipline makes little sense when divorced from the profession that gives it meaning." (Park, 1998, p. 214).

Park's second point, the "Dark Side of Title IX" noted that despite apparent gains for women in athletics, the overall trend in physical activity is more elite, less for the masses. Park noted the lack of a unified organization or identity in her third point, "Associates, Allies, and other Arrangements." As Park clearly noted, we are not in line with Homans' vision; kinesiology is not integrative-as a discipline, as a profession, or as inclusion.

Rikli (2006) presented similar views, with stronger emphasis and current illustrations. She noted that, over the past 100 years (kinesiology) “...lost much of its unified mission and focus as an integrated field of study." Focusing on Park's third point, Rikli called for establishing an organizational structure and identity for kinesiology "....as one way of...contributing to a unified, recognized, and vitally important academic field of study" (Rikli, p. 307). The AAKPE followed Rikli's call in their 2006 conference theme- "Kinesiology: Defining the Academic Core of our Discipline" (Reeve, 2007). The conference purported to cover the unified knowledge base (core), subdisciplinary contributions to the overarching discipline, the central focus, and relationship to professions. As a participant in the conference, I found much discussion, but few solutions and virtually no integration. Some subspecialists did not identify with the larger kinesiology field; "professionals" and subdisciplinary specialists often spoke different languages, and seldom connected. However, several kinesiology scholars and leaders from NAKPEHE and AAKPE are taking steps to re-connect and perhaps form an organization to bring the kinesiology house back together. 
Considering Homans' vision and all the advice of early leaders and current scholars, the three-pronged integration theme seems the clear and obvious key to sustaining kinesiology in higher education.

\section{Integration as an Academic Discipline}

The next sections provide more detail on the integration theme and inter-related three key points. The first step in sustaining kinesiology in higher education is integration as an academic discipline with a clear, unified focus on physical activity. Then, we must have academic excellence in all four forms of scholarship described by Boyer (1990) — discovery, integration, application, and teaching. The scholarship of discovery, the creation of new knowledge, is necessary to any academic area. In kinesiology, that involves subdisciplinary research (funding preferred). Clearly, we must have subdisciplinary research to advance the knowledge base. Just as clearly, in today's university we must seek external funding to support that research. But, that's not enough for scholarly excellence in kinesiology. We also need truly integrative interdisciplinary research to address relevant issues in kinesiology and physical activity.

The scholarship of integration is most relevant to the central message of this paper, and as argued in the following section, integration is the most essential scholarship to sustaining kinesiology. The scholarship of application, which involves research-into-practice, clearly is relevant and necessary for a professional discipline. Not only is it important that scholars in universities engage in scholarship of application, but practicing professionals can and should engage in the scholarship of application. Finally, to sustain kinesiology as a professional discipline, the scholarship of teaching is clearly needed in higher education, where education and development of future professionals takes place.

As Boyer emphasized, all forms of scholarship are inextricably connected. Although all forms are needed and connected, integration is the essential scholarly base, and the one that connects all others in academic kinesiology.

The scholarship of integration, as defined by Boyer (1990, pp. 18-19) involves:

...scholars who give meaning to isolated facts, putting them in perspective...making connections across disciplines, placing specialties in larger context, illuminating data in a revealing way, often educating nonspecialists, too...serious, disciplined work that seeks to interpret, draw together, and bring new insight...It is through connectedness that research ultimately is made authentic.

\section{Integration in Academic Kinesiology: Missing Link}

Despite its essential role, integration is a missing link in kinesiology. Integrative scholarship is missing in the "big time" Research I universities, and in the "wannabe" strivers for the big time. 
Scholarly values in higher education are narrow. Specifically, we value discovery, narrow methods, and increasingly fundability_regardless of other scholarly criteria. The focus on discovery, with narrow scientific paradigms and fundability over scholarly criteria, is not at all unique to kinesiology. Indeed, kinesiology must deal with those constraints and contribute to sustain itself in the university. However, the focus on discovery and lack of integrative scholarship presents a unique problem to kinesiology. Without a common, unified focus on physical activity, and the integrative scholarship that connects subdisciplines, kinesiology has no academic core.

Few major research university programs have integrative kinesiology. Some former kinesiology programs call themselves integrative physiology. As a nonphysiologist, I am not certain what is integrated - but I do not believe that it is kinesiology. Several programs include applied exercise physiology, applied sport psychology, or perhaps applied motor behavior (by those few scholars following the model of Bob Christina). But, those applied subareas are not applied kinesiology.

Not only is kinesiology split into subareas, but even subareas have further splits. For example, as both Mark Fishman and Bev Ulrich noted at the 2006 AAKPE conference, motor behavior is divided into three areas somewhat artificially. Fishman (2007) argued that there is no good justification for separating motor learning, control, and development, as there is significant overlap in scientific issues, theories, and methods. Ulrich (2007) argued that the traditionally separate areas of motor development, control, and learning cross each others' boundaries, and reiterated the call (Ulrich \& Reeve, 2005) for the areas to unite under the shared title, motor behavior. Ulrich clearly stated that the whole is greater than the sum of its parts, and as a unified area, motor behavior adds impact by creating more integrated approaches to solving problems. Ulrich extended a challenge to the larger kinesiology area in arguing that if we are to help students understand, integrate, and apply information, then we must make the effort to integrate our own subdisciplinary content with the other subdisciplines of kinesiology.

My subdisciplinary area of sport and exercise psychology is my personal pet peeve. The sport psychology/exercise psychology split that is often accepted in the subdiscipline is artificial and destroys the integrative nature of both the subdiscipline and kinesiology. Sport and exercise are not dichotomously divided, but include diverse, overlapping activity contexts. Physical activity would better describe the scope of contexts without creating categories that move us into separate camps. As others have suggested for kinesiology, and as McCullagh noted in her 2006 AAKPE talk (McCullagh \& Wilson, 2007), psychology of physical activity is more encompassing and more appropriate. Moreover, both sport and exercise are labels that suggest an elite focus rather than more inclusive physical activity. Psychological theories, content, and methodologies clearly cross contexts, as motivation models, social influence, etc. operate in Olympic events, PE classes, and cardiac rehabilitation exercise programs. Most of all, subarea labels suggest and promote division rather than the integration that would serve the field. Regardless of the label (sport psychology, sport and exercise psychology, psychological kinesiology), our subdiscipline should be an integrative psychology of physical activity, connecting with motor behavior and other subdisciplinary areas while contributing to a larger integrative kinesiology discipline. 
Integrative scholarship is further limited in major universities by the limited range of multi-disciplines. Many departments have few subdisciplinary areas, usually biosciences, and thus, do not have much to integrate. Others have split or dispersed into departments that do not share a common core or perspectives. For example, history is history, and socio-cultural sport studies has become an endangered species in university kinesiology departments. Very few departments have history scholars; some have history content, but that is seldom taught by specialists and seldom truly integrated. Moreover, for the larger kinesiology discipline, there are few historical-cultural scholars to build the subdisciplinary knowledge base and advance understanding of kinesiology from an historical or socio-cultural perspective.

With a few exceptions, kinesiology as an integrative discipline is nearly extinct in major universities with a research mission; if kinesiology departments exist, they seldom take a "big picture" (integrative) view. Typically, university kinesiology programs have no integrative courses, projects, or content, and no faculty with integrative perspectives to promote integrative perspectives. We might ignore the major research universities, but without a kinesiology presence in those institutions, we have little chance of sustaining kinesiology in higher education. Those major research university sites are the primary doctoral-granting institutions.

Although major research universities are the primary sites for preparing future (kinesiology) faculty, little attention is given to anything but the research role. Curricula are narrow with little breadth, let alone integration; in short, there is no apparent intent to prepare future faculty for kinesiology. Nationally, higher education organizations and major universities have recognized the larger issues related to faculty preparation and development. The Preparing Future Faculty (PFF) initiative was launched in 1993 as a partnership between the Council of Graduate Schools and the Association of American Colleges and Universities as a national movement to transform the way aspiring faculty members are prepared for their careers (see http://www.preparing-faculty.org/). PFF programs provide doctoral students (future faculty) with opportunities to observe and experience faculty responsibilities at a variety of academic institutions with varying missions, diverse student bodies, and different expectations for faculty. PFF programs address the full scope of faculty roles and responsibilities, including teaching, research, and service, emphasizing how expectations often differ in different campus settings. Kinesiology professionals in higher education should be visible and active in programs such as PFF, and at least, we can take advantage of the resources and connections to actively prepare future faculty in kinesiology. But, before we can prepare future faculty, we must have an integrative academic discipline.

So far, I have described the absence of essential integrative scholarship at the major universities, but professional programs at predominantly undergraduate and masters institutions are not any more integrative. Many are striving to imitate and move up to the "majors" and adding research emphasis, while also continuing to prepare professionals. I might argue that while many programs are teaching undergraduates, they may not be preparing professionals. Integrative disciplinary knowledge is essential for professional preparation. While the major university programs value discovery, the professional programs value (direct) application. But, it's not clear what is applied. The approach in many professional training programs seems to be focused on competencies and technical skills (how to), often dictated by 
outside agencies rather than by academic kinesiology. "Professional" requirements crowd the program, so there is limited kinesiology "core." In recently discussing programs with a faculty member in a predominantly undergraduate institution with a professional program, I asked about the core kinesiology courses. She reported that there are no core courses taken by students in the separate sport management, athletic training, and fitness concentrations of her department. Such programs lack a necessary discipline base; the discipline-profession link is broken.

Integration is the missing but essential link for all kinesiology programs in higher education. Integration links discovery to application; integration links scholarship to professional practice; and integration defines kinesiology's unique academic role in higher education.

\section{Integration as a Professional Discipline: Scholarship and Practice}

As well as academic integrity, integration of scholarship and practice is necessary to sustain kinesiology as a professional discipline. Professionals (e.g., physical education teachers, health/fitness instructors) use integrated knowledge from the full range of disciplines (and more). However, that does not imply that professionals use all specialized scholarly knowledge. As my social psychology hero, Kurt Lewin (1951) stated, "there is nothing so practical as a good theory"...meaning that it is not the facts, but the underlying principles that are useful. Theories apply across the range of situations encountered in the real world, and can be adapted by professionals. Taking an example from the psychology area, if you understand self-efficacy theory - that small successes build efficacy and motivation, and that actual experience is a stronger source of efficacy than just telling someone they can do it - then you can apply that principle and find ways to provide the opportunity for mastery experiences in your PE class or rehabilitation program. At the 2006 AAKPE conference, Judy Rink, discussing the role of disciplinary knowledge for those going into professional careers as physical education teachers emphasized less-is-more. Rink (2007) used the analogy, "If someone asks what time it is, do you tell then how to make a watch?" to describe knowledge presentation in many subdisciplinary kinesiology courses. As Rink noted, knowledge development in the subdisciplines has resulted in overspecialization; we know more, but basic knowledge has been replaced with specialized knowledge that has little relevance for the nonspecialist, such as the future PE teacher or fitness professional.

To foster professional development and the integration of discipline-profession, we need to emphasize practical theories-guidelines versus facts. Faculty teaching subdisciplinary courses might continually remind themselves that less is more, and focus on ways to make basic knowledge and practical theories "real" to our future professionals. For example, courses might require students to problem-solve in real world contexts, a competency that will serve them well in later adaptive, reflexive professional practice.

Integration of the academic discipline and professional practice is not only needed for training future professionals, but such integration is essential for public service and support. Public health and social problems are complex, multifaceted, and cross disciplinary boundaries, calling for integrated approaches. The National 
Institutes of Health (NIH), the beacon for Research I institutions, currently promotes its "Roadmap" (http://nihroadmap.nih.gov/), which is a call for integrative, joint approaches to public health issues that cannot adequately be addressed by single agencies.

Integrative approaches are needed to communicate with the public and policymakers to gain support, as Krahenbuhl (1998) advocated. Translational research for public health policymakers is another major NIH call, and several researchers from nonkinesiology disciplines have extended the call for research that actually puts results into practice. For example, Sommer (2006) argued for required dual dissemination of results; that is, findings would not only be distributed to other scholars through typical journals (the norm for most research), but also simultaneously to the wider public and policymakers. Disciplinary scholars must do this. If not us-who? That's rhetorical; there is no one else to do the integrative scholarly work to translate and connect our research to professional practice.

\section{Integration as Inclusion and Social Justice}

Integration as an academic discipline and integration of the discipline and profession are both clear, often repeated directions from our leaders. Less obvious, but I believe even more important to our sustainability, is integration as inclusion and social justice. This is my current campaign slogan, and a message I have repeated whenever I have had the opportunity. Inclusion means physical activity for all, with no more left-outs. Such inclusion clearly contributes to kinesiology's professional mission. To move beyond inclusion to social justice, we have action and advocacy, which contributes to the larger university and public mission.

In comparison with other academic disciplines, kinesiology has an edge in our unique contribution as an integrative professional discipline. Kinesiology professionals serve the public and promote health and well-being in individuals and society.

I'll expand on the "Physical Activity for All" theme. Research confirms health benefits and physical activity is cited as the leading public health indicator in Healthy People 2010 (USDHHS, 2000), but participation is limited by gender, race, class, and especially by physical attributes. Physical activity generally decreases across the adult lifespan, and the decreases (and increasing inactivity) interact with gender, race, and class. Generally, men are more active than women, racial/ethnic minorities are less active across all age groups, and young adult women (particularly African American women) are one of the most inactive populations in the U.S. (Kimm et al., 2002; Pratt et al., 1999; USDHHS, 2000). Crespo, Ainsworth, Keteyian, Heath, and Smit (1999), used a national database to examine social class and found inactivity more common in less privileged social classes, and females more inactive in all social class groups. Crespo (2005) cites the linked health disparities and low activity levels for minority groups, and argues that the potential public health benefit of a physically active lifestyle for racial/ethnic minorities cannot be ignored.

In sum, physical activity is the key to positive health and quality of life; inactivity is a risk factor; and thus, lifetime physical activity is the base for healthy lives. But, physical activity/inactivity is not equal; physical activity disparities parallel the widely cited disparities in health. Activity levels are lower for underrepresented 
and minority groups - those who most need physical activity and can benefit the most. Moreover, I argue that all have a right to physical activity as a public health and social justice issue, and it is our professional responsibility in kinesiology to secure that right.

Following is my summary of the state of inclusion and social justice for the subdisciplinary area of sport/exercise psychology (intentionally linked by “"”). Here, I extend this summary to other kinesiology subdisciplines as well as the overall kinesiology professional discipline.

In terms of scholarship, we have no progress (not in sport/exercise psychology or other subdisciplinary areas). Kinesiology research is noninclusive and narrow in scope, methods, and paradigms. Multicultural issues are neglected, and there is little critical analysis.

Professional practice is elite, and has become increasingly so in sport/exercise psychology in recent years. The focus is on elite (professional/intercollegiate athletes, physically skilled, clients in elite programs). In comparison to earlier times, kinesiology professionals pay less attention to public, diverse participants (no more "a game for every girl, every girl in a game"). Education and training in sport/exercise psychology focuses on elite practice with little connection to wider kinesiology professional areas. Other subdisciplinary areas are no more inclusive, and often do not connect to any (elite or inclusive) professional practice. Generally kinesiology has a limited social/cultural scholarly base, and educational/training programs take a "tech" approach. Action in the public interest, which implies direct attention to social justice and public health, is not in the picture.

Given that we are currently ignoring integration as inclusion, almost any moves toward inclusion and social justice will enhance and sustain kinesiology. In our scholarship, we can widen the lens to include multicultural issues and critical analyses. Similarly, scholars can use and recognize multiple methods and methodologies. Traditional science focuses on internal validity and controls. Stanley Sue (1999) argued that traditional psychological research models overemphasize internal validity and hinder ethnic minority research. To move forward, Sue advocates that: (a) all research studies address external validity and specify populations to which findings are applicable; (b) different research approaches, including qualitative and ethnographic methods be appreciated; and (c) the psychological meaning of ethnicity or race be examined in ethnic comparison. Kinesiology researchers should similarly attend to external validity and reconnect with professionals. For example, we might be as quick to draw attention to the limits of the experiment with a small number of physically fit kinesiology students in a controlled lab context as we are to note the limits of action research in community programs.

In professional practice and education programs we can follow the lead of other professional disciplines in promoting multicultural scholarship, and the development of cultural competencies in professionals and future professionals. Culturally competent professionals act to empower participants and challenge restrictive social structures. Multicultural competencies are often cited in human services and health care professions, but multicultural competencies are essential for anyone working with others, and certainly for kinesiologists in all professional roles. Multicultural competencies include three general areas: (1) awareness of one's own cultural values and biases; (2) understanding of the client's worldviews (in all its multicultural 
complexity); and (3) development of culturally appropriate intervention strategies (Mio et al., 2006). Multicultural competency enhances professional practice, and leads to mutually enriching interactions.

The American Psychological Association (APA) has recognized the key role of multicultural competencies in fulfilling psychology's mission to promote health and well-being. APA's (2003) multicultural guidelines provide a model for kinesiology professionals. By substituting kinesiology for psychology in the guidelines listed below, we have a model for a more inclusive, empowering kinesiology.

APA (2003) Multicultural Guidelines

\#1: Psychologists [kinesiologists] are encouraged to recognize that, as cultural beings, they may hold attitudes and beliefs that can detrimentally influence their perceptions of and interactions with individuals who are ethnically and racially different from themselves.

\#2: Psychologists are encouraged to recognize the importance of multicultural sensitivity/responsiveness, knowledge, and understanding about ethnically and racially different individuals.

\#3: As educators, psychologists are encouraged to employ the constructs of multiculturalism and diversity in psychological education.

\#4: Culturally sensitive psychological researchers are encouraged to recognize the importance of conducting cultural-centered and ethical psychological research among persons from ethnic, linguistic, and racial minority backgrounds.

\#5: Psychologists strive to apply culturally-appropriate skills in clinical and other applied psychological practices.

\#6: Psychologists are encouraged to use organizational change processes to support culturally informed organizational (policy) development and practices.

All kinesiology professionals can serve the public interest by promoting physical activity for health and well-being for all (for girls/women, racial/ethnic minorities, those with disabilities, and all who do not "fit"), and by highlighting cultural competence-demonstrating a genuine acceptance and respect for cultural differences_as our professional responsibility.

\section{Sustaining Kinesiology in Higher Education in the 21st Century: Conclusions}

Can we sustain kinesiology in higher education in the 21st century? Roberta Park (1998) argued that: it is time to recapture something akin to the shared vision that motivated early leaders. As Rikli (2006) notes, it is past time. We can look to Amy Morris Homans for that vision. In returning to the three related and integrated key points, sustaining kinesiology in higher education requires: 
- Integration as an academic discipline. That is, kinesiology must have academic excellence with a unified focus on physical activity. Academic excellence demands that we value, and act like we value, integrative scholarship, to highlight kinesiology's unique contribution in higher education.

- Integration as a professional discipline. As Park (1998) reminded us, it is the profession that makes the discipline indispensable. Like medicine and law, kinesiology must retain its professional mission and disciplinary scholars must translate and disseminate our research. An integrative curriculum (less-is-more) in pre-professional programs can help connect the discipline-profession, to further sustain kinesiology's unique contribution.

- Integration as inclusion and social justice. All kinesiology professionals (researchers at major universities, teacher-educators, PE teachers, fitness professionals) must promote inclusive physical activity for all. That involves making a commitment to public welfare, serving the larger mission, and making kinesiology indispensable to higher education and to the larger society.

Finally, as Homans did, we must build for the future. A sustainable kinesiology requires future leaders with commitment to kinesiology as a... unified, recognized, and vitally important academic field of study (Rikli, 2006, p. 307). Such an integrative kinesiology can continue to fulfill Homans' vision and lift all of us to a higher level of health and vigor.

\section{References}

American Academy of Kinesiology and Physical Education. (2006). (http://www.AAKPE.org) American Friends Service Committee. (http://www.afsc.org/trade-matters/learn-about/glossary.htm)

American Psychological Association. (2003). Guidelines on multicultural education, training, research, practice and organizational change for psychologists. American Psychologist, 58, 377-402.

Association for the Advancement of Sustainability in Higher Education. (AASHE). (http:// www.aashe.org)

Boyer, E. (1990). Scholarship reconsidered: Priorities of the professoriate. Princeton, NJ: The Carnegie Foundation.

Chronicle of Higher Education. (Oct. 20, 2006). What is a sustainable university? 53(9), p. A8.

Crespo, C.J. (2005). Physical activity in minority populations: Overcoming a public health challenge. The President's Council on Physical Fitness and Sports Research Digest, Series 6, No. 2 (June).

Crespo, C.J., Ainsworth, B.E., Keteyian, S.J., Heath, G.W., \& Smit, E. (1999). Prevalence of physical inactivity and its relations to social class in U.S. adults: Results from the Third National Health and Nutrition Examination Survey, 1988-1994. Medicine \& Science in Sports \& Exercise, 31, 1821-1827.

DANTES project. (http://www.dantes.info/Projectinformation/Glossary/Glossary.html)

Fishman, M.G. (2007). Motor learning and control foundations of kinesiology: Defining the academic core. Quest, 59, 67-76.

Forker, B.E. (1986). Leadership: The key ingredient. Quest, 38, 87-94.

Kimm, S.Y.S., et al. (2002). Decline in physical activity in black girls and white girls during adolescence. New England Journal of Medicine, 347, 709-715. 
Krahenbuhl, G.S. (1998). Higher education in the 21st century: The role of kinesiology and physical education. Quest, 50, 108-115.

Lewin, K. (1951). Field theory in social science. New York: Harper \& Brothers.

Magyar, T.M. (2006). Toward a transdisciplinary approach to busting the "barnacle" lifestyle: Implications for kinesiology in higher education. Chronicle of KPEHE, 17 (1) (Feb.), p. 3, 16-17.

McCullagh, P. \& Wilson, G. (2007). Psychology of physical activity: What should students know? Quest, 59, 42-54.

Mio, J.S., Barker-Hackett, L. \& Tumambing, J. (2006). Multicultural psychology: Understanding our diverse communities. Boston: McGraw-Hill.

National Institutes of Health (NIH) "Roadmap" (http://nihroadmap.nih.gov/)

Park, R.J. (1998). A house divided. Quest, 50, 213-224.

Pratt, M., Macera, C.A., \& Blanton, C. (1999). Levels of physical activity and inactivity in children and adults in the United States: Current evidence and research issues. Medicine \& Science in Sport \& Exercise, 31, 526-533.

Preparing Future Faculty (PFF) initiative. (http://www.preparing-faculty.org/)

Reeve, T.G. (2007). Kinesiology: Defining the academic core of our discipline. Quest, 59, $1-4$.

Rikli, R.E. (2006). Kinesiology—A "homeless" field: Addressing organization and leadership needs. Quest, 58, 288-309.

Rink, J. (2007). What knowledge is of most worth? Perspectives on kinesiology from pedagogy. Quest, 59, 100-110.

Sommer, R. (2006). Dual dissemination: Writing for colleagues and the public. American Psychologist, 61, 955-958.

Spears, B. (1986). Leading the way: Amy Morris Homans and the beginning of professional physical education for women. New York: Greenwood Press.

Sue, S. (1999). Science, ethnicity, and bias: Where have we gone wrong? American Psychologist, 54, 1070-1077.

Sustainable table. (http://www.sustainabletable.org/intro/dictionary/)

Time. (Oct. 30, 2006). Hot jobs, cold jobs. Vol. 168, No. 18.

Ulrich, B. (2007). Motor development: Core curricular concepts. Quest, 59, 77-91.

Ulrich, B.D. \& Reeve, T.G. (2005). Studies in motor behavior: 75 years of research in motor development, learning, and control. Research Quarterly for Exercise and Sport, 76 (Suppl. 2), S62-S70.

U.S. Dept of Health and Human Services (USDHHS) (2000). Healthy People 2010. Washington: DHHS. 